\title{
ESTABILIZAÇÃO DA TUTELA ANTECIPADA ANTECEDENTE NO PROCESSO CIVIL BRASILEIRO: UM PRIMEIRO BALANÇO
}

\author{
STABILIZATION OF THE PROVISIONAL TUTLE IN THE BRAZILIAN CIVIL \\ PROCESS: A FIRST BALANCE SHEET
}

\begin{abstract}
Alexandre de Castro Catharina
Doutor em Sociologia pela Universidade Cândido Mendes/UCAM. Professor de Direito Processual Civil da Universidade Estácio de Sá/UNESA. Pesquisador Produtividade da UNESA. Coordenador do Observatório de Cultura Jurídica Processual e Democratização do Processo, Campus Nova América, UNESA, RJ. alexandre.catharina@hotmail.com.br
\end{abstract}

\begin{abstract}
Resumo: A estabilização da tutela provisória é uma das principais apostas do Código de Processo Civil de 2015 para se alcançar a efetividade da jurisdição na fase cognitiva. Neste sentido, se faz necessário refletir sobre a adequação do tratamento dado ao tema pelo legislador processual e, principalmente, se a inovação normativa vem produzindo efeitos práticos na dinâmica da atividade judicial. Partindo dessa premissa, o principal objetivo do trabalho é fazer um balanço da estabilização da tutela provisória no CPC, num primeiro momento, e verificar se a inovação legislativa proposta provocou impactos na prática dos principais tribunais de justiça do país. A metodologia utilizada no trabalho é qualitativa documental, com ênfase na análise de algumas decisões judiciais, articulada com levantamento bibliográfico.
\end{abstract}

Palavras-chave: Tutela provisória. Estabilização. Efetividade do processo.

Abstract: The stabilization of provisional custody is one of the main bets of the 2015 Code of Civil Procedure to achieve the effectiveness of jurisdiction in the cognitive phase. In this sense, it is necessary to reflect on the adequacy of the treatment given to the theme by the procedural legislator and, especially, if the normative innovation has been producing practical effects on the dynamics of judicial activity. Based on this premise, the main objective of the paper is to take stock of the stabilization of provisional custody in the CPC, at first, and to verify if the proposed legislative innovation had impacts on the practice of the main courts of the country. The methodology used in the work is qualitative documentary, with emphasis on the analysis of some court decisions, articulated with bibliographic survey.

Keywords: Provisional Guardianship. Stabilization. Effectiveness of the process.

Para citar este artigo (ABNT NBR 6023:2018)

CATHARINA, Alexandre de Castro. Estabilização da tutela antecipada antecedente no processo civil brasileiro: um primeiro balanço. Revista Thesis Juris - RTJ, São Paulo, v. 9, n. 1, p. 121-144, jan./jun. 2020. http://doi.org/10.5585/rtj.v9i1.16784. 
CATHARINA, Alexandre de Castro. Estabilização da tutela antecipada antecedente no processo civil brasileiro: um primeiro balanço

\section{Introdução}

Propiciar ao jurisdicionados técnicas processuais que assegurem a resolução adequada e célere dos conflitos de interesses, mediante um processo cooperativo e justo, é um dos principais objetivos da ciência processual na contemporaneidade. A entrega da tutela jurisdicional efetiva, e num tempo razoável, se constitui em um direito fundamental, tanto no processo civil como nos processos penal e trabalhista, conforme interpretação teleológica do art. 5, LXXVIII da Constituição Federal de 1988. Neste contexto, o Código de Processo Civil de 2015 deu tratamento mais sistematizado às tutelas provisórias, unificando, em um só Livro (V), as tutelas de evidência, as tutelas antecipatórias e as tutelas cautelares, simplificando o regramento da temática com a finalidade de dar maior aplicabilidade às tutelas cognitivas sumárias.

A novidade de maior relevo trazida pelo CPC/2015, da perspectiva do direito fundamental ao amplo acesso à justiça ${ }^{1}$ (CAPPELLETTI, 1999), foi a denominada tutela antecipada antecedente sem a formulação do pedido principal. Trata-se das hipóteses a partir das quais o autor formula requerimento de tutela antecipada antecedente e, após o deferimento da medida, observado o contraditório, os autos são arquivados sem a formulação de pedido principal. É a denominada estabilização da tutela provisória (antecipatória) antecedente, cuja eficácia e funcionalidade é discutida há tempos, de lege ferenda, no âmbito do direito processual.

O arquivamento de tutela provisória não pode ser considerado como uma inovação, do ponto de vista da prática forense, no Judiciário brasileiro. As denominadas cautelares satisfativas, que surgiram como arranjo jurisprudencial e doutrinário na vigência do CPC/1973, eram utilizadas por demandantes que necessitavam de uma medida liminar, mas não tinham interesse em prosseguir com a demanda para apreciação de pedido principal. Embora a doutrina tradicional desse destaque à dimensão acessória da tutela cautelar, vinculada necessariamente a uma demanda principal, as situações da vida demonstraram que ocasiões há em que um provimento judicial, ainda que precário, pode ser eficaz para preservar ou mesmo implementar uma situação jurídica premente.

Para melhor compreender a hipótese, pense no caso de um determinando cidadão que, ao participar de um concurso público, é eliminado do certame, indevidamente, em razão da falta de requisitos ou reprovação indevida em testes físicos. Considerando que a etapa seguinte seria

\footnotetext{
${ }^{1}$ Para Mauro Cappelletti, o acesso à justiça é um direito fundamental e deve ser assegurado através da tutela adequada dos direitos.
}

Revista Thesis Juris - RTJ, São Paulo, v. 9, n. 1, p. 121-144, jan./jun. 2020 
CATHARINA, Alexandre de Castro. Estabilização da tutela antecipada antecedente no processo civil brasileiro: um primeiro balanço

realizada em alguns dias, o candidato deflagrava uma medida liminar com objetivo, exclusivo, de realizar a etapa do certame. Realizada a etapa, o candidato não mais tinha interesse em prosseguir com a demanda uma vez que conseguiu realizar a respectiva etapa do certame, sendo arquivados os autos da referida medida. A medida liminar concedida era denominada de cautelar satisfativa.

A estabilização da tutela antecipada antecedente em muito se assemelha, em termos práticos, à denominada cautelar satisfativa. Apesar das semelhanças, a tutela antecipada antecedente, independente de pedido principal, foi regulamentada pelo CPC/2015 com certo apuro técnico, o que requer análise acurada acerca da adequação do tratamento normativo dado ao tema, assim como investigar se a inovação legislativa encontra amparo na prática judiciária. Estes são os objetivos iniciais deste trabalho.

Pretende-se, portanto, analisar o impacto do instituto da estabilização da tutela antecipada antecedente em nosso ordenamento processual em pelo menos dois vetores. $\mathrm{O}$ primeiro balanço sobre o instituto será normativo e teórico. Compreender o tratamento sistemático dado ao tema pelo código e como esse tratamento foi recepcionado pela literatura especializada é imprescindível. Para tanto será empregado, como método de pesquisa, o levantamento bibliográfico.

O segundo balanço acerca do instituto, e principal objetivo deste trabalho, concerne à sua eficácia em nossa prática judiciária. Analisar acertos e equívocos do tratamento normativo dado a um instituto processual não pode prescindir de pesquisa empírica sobre a sua eficácia. É neste sentido que, através da metodologia de pesquisa qualitativa documental, serão analisadas decisões judiciais proferidas no ano de 2019, no âmbito de alguns tribunais de justiça das regiões do país, de modo a identificar como o instituto da estabilização da tutela antecipada antecedente vem sendo tratado na prática judiciária brasileira.

O recorte temporal decorre do necessário tempo de assimilação do instituto pelos profissionais do direito e das respectivas instituições jurídicas. Os primeiros anos de vigência do código foram essenciais para compreensão das inovações levadas a efeito. Entre 2018 e 2019, os tribunais começaram a julgar recursos cujo mérito abordava a aplicação/adequação de diversos institutos do Código de Processo Civil de 2015, motivo pelo qual se optou por analisar decisões proferidas no ano de 2019.

Considerando os limites deste trabalho, a amostra utilizada na pesquisa compreende decisões proferidas por um ou dois tribunais de justiça de cada região do país. Embora a amostra não alcance, por certo, todos os tribunais da Federação, a amostra nos permite inferir as principais questões sobre o instituto que são levantadas em todas as regiões do país. Analisar 
CATHARINA, Alexandre de Castro. Estabilização da tutela antecipada antecedente no processo civil brasileiro: um primeiro balanço

decisões judiciais de um tribunal ou mesmo de uma região limita, sobremaneira, a análise em razão das peculiaridades regionais e dimensões culturais de cada estado.

Foram, com efeito, analisadas decisões judiciais proferidas no âmbito dos tribunais de justiça dos estados do Amazonas, Distrito Federal, Ceará, Maranhão, Mato Grosso do Sul, Minas Gerais, Pará, Paraná, Rio de Janeiro, Rio Grande do Sul, Santa Catarina, São Paulo e Sergipe. A metodologia de coleta de dados será abordada por ocasião da análise dos resultados.

Contemplar tribunais de todas as regiões, ainda que não alcance a integralidade, nos permite identificar, depuradas as especificidades culturais de cada região, as principais questões acerca da aplicabilidade e eficácia do instituto, assim como as dificuldades sobre adequação legislativa que surgem da prática forense. Esta análise não só contribui para o refinamento teórico do instituto como também para seu aprimoramento enquanto técnica processual. Segundo Becker (2007), conhecer parte de um fenômeno nos permite, também, inferir sobre o fenômeno como um todo. A pesquisa qualitativa, portanto, é essencial neste sentido.

Por fim, é importante esclarecer que a amostra contempla apenas provimentos jurisdicionais da justiça estadual em razão do volume de demandas judiciais propostas e da diversidade de áreas do direito tratada no âmbito desse ramo do Poder Judiciário. Tal diversidade quantitativa e qualitativa de processos nos permitirá alcançar maior número de casos em que o instituto foi mobilizado. A partir dos dados coletados, utilizamos a abordagem indutiva para nortear as principais conclusões do trabalho.

\section{Estabilização da tutela antecipada no CPC/2015}

Antes de analisar o impacto da estabilização da tutela antecipada na dinâmica judiciária, faz-se necessário abordar, de forma panorâmica, o desenvolvimento legislativo do instituto na processualística brasileira para, na sequência, abordar o tratamento dado à tutela provisória (antecipada e cautelar) no código.

A antecipação de tutela surgiu no ordenamento processual civil brasileiro através da Lei n 8.952/1994, que deu nova redação ao art. 273, do Código de Processo Civil de 1973, no sentido de autorizar a antecipação dos efeitos da decisão final no âmbito do procedimento comum ordinário. É importante ressaltar que a antecipação de tutela já era admissível em procedimentos especiais, como deferimento de alimentos provisórios, nos termos do art. $4^{\circ}$, da Lei ${ }^{\circ}$ 5.478/1968 e reintegração de posse, liminarmente, nas ações possessórias, conforme dispunha o art. 928 do Código de Processo Civil de 1973. A inovação trazida pela Lei no 8.952/1994 foi no sentido de generalizar as possibilidades de antecipação de tutela nas causas 
CATHARINA, Alexandre de Castro. Estabilização da tutela antecipada antecedente no processo civil brasileiro: um primeiro balanço

que tramitavam pelo procedimento comum, sumário ou ordinário, eliminando, neste particular, resquícios de formalismos processuais desnecessários (BARBOSA MOREIRA, 2004).

A antecipação da tutela promoveu, no campo doutrinário, importante virada epistemológica promovendo significativa mudança de paradigma, no sentido proposto por Kuhn (2017). Esse fato deslocou o eixo de análise da tutela jurisdicional, com ênfase na cognição exauriente, vertical e profunda, trazendo para o centro do debate científico as técnicas de cognição sumária, em que a antecipação de tutela se constitui em uma das principais técnicas processuais direcionada à efetividade da tutela jurisdicional.

A perspectiva teórica de Kazuo Watanabe (2012) é fundamental neste contexto histórico. Para Watanabe (2012), a cognição se desdobra em exauriente e sumária. A cognição aprofundada, vertical, é denominada pelo autor de cognição exauriente. Por outro lado, a cognição sumária, é horizontal, limitada e parcial, assentada num juízo de probabilidade, como ocorre na apreciação da antecipação de tutela. Essa ambivalência do conceito de cognição orientou a compreensão e interpretação do instituto sobre a antecipação de tutela ao longo de seu desenvolvimento normativo.

Em 2002, a Lei ${ }^{\circ}$ 10.444/2002 ampliou o escopo da tutela antecipada para permitir a antecipação em casos em que a pretensão do autor restar incontroversa, após a contestação do réu, nos termos da redação do art. $273, \S 6^{\circ}$ e viabilizou, nos termos da redação do art. $273, \S 7^{\circ}$ do Código de Processo Civil de 1973, a fungibilidade entre as tutelas cautelar e antecipada, estabelecendo, por assim dizer, um regime das tutelas de urgência (cautelar e antecipada) no direito processual civil brasileiro.

Neste período, entre 1994 e 2002, a doutrina do direito processual civil brasileiro elaborou consistente edifício teórico acerca das tutelas de urgência, estabelecendo, de forma criteriosa e científica, a distinção entre tutela cautelar e tutela antecipada. Neste sentido, Leonardo Greco (2014, p. 300) destaca que a doutrina tradicional elaborou, cientificamente, as principais características das tutelas de urgência, em especial a tutela cautelar, que são inércia, provisoriedade, fungibilidade, revogabilidade, instrumentalidade e cognição sumária. Segundo o autor, a releitura dessas características será essencial para a adequada interpretação do regime das tutelas provisórias no âmbito do Código de Processo Civil de 2015, sobretudo no que concerne à estabilização da tutela antecipada antecedente ${ }^{2}$.

\footnotetext{
${ }^{2}$ No que tange à estabilização da tutela antecipada, não há que se falar em fungibilidade. É imprescindível, no âmbito da tutela cautelar, a formulação do pedido principal, o que inviabiliza sua estabilização. Com acerto, Leonardo Greco (2014) afirma que no regime das tutelas provisórias no Código de Processo Civil de 2015 as referidas características das tutelas de urgência, elaboradas na vigência do Código de Processo Civil de 1973, precisam ser revistas.
} 
CATHARINA, Alexandre de Castro. Estabilização da tutela antecipada antecedente no processo civil brasileiro: um primeiro balanço

Passemos então à análise normativa do instituto no CPC/2015. A tutela provisória está regulamentada no Livro V, mais especificamente nos Títulos I, II e III do CPC. O Título I cuida das Disposições Gerais acerca da tutela provisória (arts. 294 a 299), o Título II trata das tutelas de urgência, antecipada e cautelar (arts. 300 a 310) e o Título III regulamenta a denominada tutela de evidência (art. 311). Leonardo Greco (2014), ao analisar o Projeto do Código de Processo Civil de $2015^{3}$, destaca que o regramento da tutela provisória foi sistemático e consistente e que é possível delimitar, com certa clareza, os critérios estabelecidos pelo legislador processual para classificar as modalidades de tutelas provisórias.

Partindo da premissa sugerida pelo referido autor, o regime das tutelas provisórias observa os seguintes critérios: definida em razão da natureza, podendo ser tutela provisória de urgência (cautelar ou antecipada) ou de evidência; definida em razão da funcionalidade, cujo escopo pode ser no sentido de preservar ou implementar uma situação jurídica por meio do direito processual civil, podendo ser tutela cautelar ou antecipada por um lado, e tutela de urgência ou de evidência por outro, ou por fim, definida em razão de sua dimensão temporal, podendo ser a tutela provisória requerida antecedente ou incidental ao processo judicial. $\mathrm{O}$ escopo do nosso trabalho é a estabilização da tutela antecipada, razão pela qual não abordaremos, amiúde, a tutela cautelar e a tutela de evidência.

A tutela antecipatória consiste na antecipação dos efeitos dos pedidos formulados em uma determinada demanda. Presentes os requisitos para sua concessão, quais sejam probabilidade do direito alegado e perigo de dano ou risco ao resultado útil do processo, o juiz poderá antecipar os efeitos da tutela jurisdicional pretendida (art. 300). A tutela antecipada evita os efeitos das delongas processuais, assegurando maior efetividade à tutela jurisdicional. A reformulação da antecipação da tutela jurisdicional no Código de Processo Civil de 2015, com efeito, contribui para estimular maior celeridade na prestação da atividade judicial. É importante destacar que celeridade processual, nesta dinâmica processual, significa solução célere e, principalmente, integral do mérito posto em juízo (THEODORO JUNIOR; NUNES; BAHIA e PEDRON, 2015)

O código inovou ao dispor sobre a possibilidade de estabilização da tutela antecipada deferida nos casos em que o autor não formular pedido principal. É relevante destacar que a proposta de estabilizar a tutela antecipatória não é recente no Brasil. Conforme bem destacou Rosalina Costa e Yasmin Curvelo (2018), a proposta de inserção da técnica de estabilização da

\footnotetext{
${ }^{3}$ Importante destacar que, embora a análise do autor tenha como objeto o Projeto do Código de Processo Civil de 2015, suas análises permanecem pertinentes considerando que o Projeto de Lei aprovado não promoveu mudanças significativas no regramento da tutela provisória.
} 
CATHARINA, Alexandre de Castro. Estabilização da tutela antecipada antecedente no processo civil brasileiro: um primeiro balanço

tutela antecipada foi proposta, inicialmente, por Ada Pelegrini Grinover nos anos de 1997 e 2005, sem a devida acolhida pela comunidade científica e pelo legislador processual. A técnica de estabilização da tutela antecipada, independente de pedido principal, possui equivalentes no direito comparado, com experiências positivas na França e na Itália (DOTTI, 2018).

A técnica de estabilização tem como escopo dar autonomia à tutela sumária, possibilitando a resolução diferenciada de determinados conflitos de interesses que demandam solução rápida, justa e efetiva (DOTTI, 2018), cujo procedimento padrão se mostra insuficiente e inadequado. Na Exposição de Motivos do Código de Processo Civil de 2015 (SENADO, 2015), a Comissão de Juristas deixa claro que o regramento da tutela provisória, incluída a técnica de estabilização da tutela antecipada antecedente, teve como intento buscar uma resposta rápida do Poder Judiciário, não só em situações em que a urgência decorre do risco de eficácia e do eventual perecimento do próprio direito. A resposta rápida, portanto, a própria celeridade, se constitui como vetor axiológico das tutelas provisórias. Essas considerações prévias são necessárias para se compreender a intenção do legislador ao inserir a tutela antecipada em nosso ordenamento jurídico.

$\mathrm{O}$ art. 303 dispõe sobre o instituto da seguinte forma:

\begin{abstract}
Nos casos em que a urgência for contemporânea à propositura da ação, a petição inicial pode limitar-se ao requerimento da tutela antecipada e à indicação do pedido de tutela final, com a exposição da lide, do direito que se busca realizar e do perigo de dano ou do risco ao resultado útil do processo (grifo nosso).
\end{abstract}

Em outros termos, poderá o autor apresentar requerimento de antecipação de tutela antecedente sem formular pedido principal ${ }^{4}$ (MARINONI, ARENHART, MITIDIERO, 2015, p.214). Há, nesta esteira, um sistema dual (COSTA; CURVELO, 2018) em nosso ordenamento processual em que o autor poderá requerer tutela antecipada antecedente sem pedido principal e requerimento de tutela antecipada antecedente com formulação de pedido principal. Para compreender o que está proposto no código, pense nos casos em que uma pessoa vende um veículo para outra e, por algum motivo, não comunica a venda ao DETRAN. Passados alguns meses, o vendedor verifica que o veículo ainda está em seu nome e pretende, mediante requerimento de tutela antecipada, tão somente o deferimento de uma medida judicial que determina a substituição da propriedade do veículo junto ao referido órgão. Deferida a tutela antecipada e não formulado pedido principal, a tutela deferida estabilizará, postergando seus efeitos no tempo.

\footnotetext{
${ }^{4}$ Para o referido autor, o CPC/2015 autonomizou a tutela antecipada, permitindo ao autor formular somente requerimento de cognição sumária. Segundo o autor, a estabilização da tutela somente incidirá nos casos em que haja urgência de provimento jurisdicional, sendo afastada nos casos de tutela de evidência.
} 
CATHARINA, Alexandre de Castro. Estabilização da tutela antecipada antecedente no processo civil brasileiro: um primeiro balanço

Surgem, portanto, algumas indagações procedimentais. Como o requerimento deve ser formulado? Qual a natureza da decisão judicial que defere o requerimento? A decisão que defere tutela antecipada estabilizada faz coisa julgada material? Até quando poderá o autor formular pedido principal? O réu deverá ser ouvido?

$\mathrm{O}$ art. 303 dispõe que, nestes casos, deverá o autor formular na inicial o requerimento de tutela antecipada antecedente e indicar o pedido final que, eventualmente, será formulado, com a exposição da lide e a demonstração do perigo de dano ou do risco ao resultado útil do processo. Não há necessidade de se formular o pedido final, mas tão somente indicar qual seria. Para Rosalina Costa e Yasmin Curvelo (2018), o requerimento de tutela antecipada antecedente preenche dupla finalidade. A primeira concerne à possibilidade de o autor desenvolver com maior diligência o requerimento de tutela provisória antecedente, dispensando-o de maiores esforços no que tange à fundamentação do direito material. A segunda finalidade é, como consequência da primeira, evitar que o demandante elabore a petição inicial, com perda de tempo e energia, caso a medida seja indeferida e não haja interesse no prosseguimento da demanda em razão mesmo da perda do objeto (necessidade de cognição sumária).

Conforme dispõe a regra do art. $303, \S 5^{\circ}$, deverá o autor indicar expressamente que pretende somente formular requerimento de antecipação de tutela antecedente ${ }^{5}$ (DIDIER, 2017, p. 687). O código não é claro sobre as consequências processuais da ausência de indicação do autor, mas sugere a interpretação no sentido de que, se o requerimento de tutela antecedente for formulado sem ser apontado na petição inicial que não pretende formular pedido principal, o processo será extinto sem resolução do mérito após o esgotamento do prazo de 15 dias a contar do deferimento da medida ${ }^{6}\left(\operatorname{art.} 303, \S 2^{\circ}\right)$.

A tutela antecipada antecedente deferida pelo juiz, sem formulação de pedido principal, nos exatos termos do art.303, será estabilizada após o esgotamento do prazo para interpor recurso contra a decisão que deferiu a medida. Sobre esse aspecto, o Superior Tribunal de Justiça, no julgamento do REsp 1760966/SP, julgado pela $3^{\text {a }}$ Turma em dezembro de 2018, interpretou o art. 304 do CPC no sentido de que, se o réu apresentar tempestivamente a contestação, a interpretação extensiva sugere que a tutela antecipada não deve ser estabilizada ${ }^{7}$ (MARINONI, ARENHART, MITIDIERO, 2015), ainda que não haja interposição de recurso de agravo de instrumento (art. 1.015, I). O referido precedente judicial é fundamental no sentido

\footnotetext{
${ }^{5}$ Trata-se de um requisito para a estabilização da tutela antecipada antecedente.

${ }^{6}$ A ausência de manifestação do requerente no sentido de prosseguimento da demanda constitui pressuposto negativo, no sentido proposto por Fredie Didier (2017), para estabilização da tutela antecipada. A simples manifestação do requerente que sugira o prosseguimento da demanda é incompatível com a estabilização.

${ }^{7}$ Entendimento sustentado pelo autor antes mesmo da edição do precedente judicial do Superior Tribunal de Justiça.
} 
CATHARINA, Alexandre de Castro. Estabilização da tutela antecipada antecedente no processo civil brasileiro: um primeiro balanço

de eliminar dúvidas acerca deste pressuposto para estabilização da tutela antecipada antecedente.

É possível delimitar, portanto, quais são os pressupostos para estabilização da tutela antecipada antecedente no Código de Processo Civil de 2015. Em primeiro lugar, deve haver requerimento expresso acerca da estabilização da tutela antecedente por parte do autor. Cumulativamente, faz-se necessário que haja interposição de recurso de agravo de instrumento contra decisão que defere a medida, ou apresentação da respectiva contestação.

A segunda indagação que se coloca em relação ao regramento da estabilização da tutela antecedente diz respeito à natureza jurídica da decisão que estabiliza a tutela antecipada ${ }^{8} \mathrm{O}$ art. $304, \S 1^{\circ}$, diz que, estabilizada a tutela antecipada, o processo será extinto. Extinção de processo na processualística brasileira se realiza por meio de sentença. O referido dispositivo legal não deixa claro qual a natureza dessa decisão.

Entretanto, o art. 1.015, I, dispõe que caberá agravo de instrumento contra decisão que deferir ou indeferir a tutela provisória, o que demonstra que o legislador optou por não diferenciar as decisões proferidas em tutela provisória, mantendo, em todos os casos, a natureza de decisão interlocutória. Com efeito, todos os julgados analisados extinguiram o processo por sentença, nos casos em que o requerido não contestou ou interpôs recurso de agravo de instrumento. Há, nessa hipótese, uma adequação do instituto por meio da prática judiciária.

Em relação à ocorrência ou não da coisa julgada material, o código é um tanto obscuro. A tutela antecipada estabilizada poderá ser revista, reformada ou invalidada no prazo de 02 anos, contados da data da extinção (art. 304, $\S 1^{\circ}$ ), conforme se depreende da leitura do art. 304, $\S 5^{9}$. Por outro lado, dispõe que a tutela antecipada estabilizada não faz coisa julgada (art. 304, $\left.\S 6^{\circ}\right)$, mas os efeitos da estabilidade somente serão afastados por decisão judicial que promover sua revisão, reforma ou invalidação no prazo de 02 anos.

Embora o Código não seja preciso no que diz respeito à via adequada para impugnar a tutela estabilizada, Fredie Didier (2017) defende que a parte interessada deverá, no referido prazo, propor ação de impugnação ou confirmação da tutela estabilizada no respectivo juízo que concedeu a medida. Se a parte ré não promover o desarquivamento e requerer a invalidação ou reforma da decisão no referido prazo, a estabilidade se torna imutável? O código não é claro nesse aspecto.

\footnotetext{
${ }^{8}$ É importante destacar que somente será estabilizada a decisão que conceder à tutela antecipada antecedente. A decisão que indefere a tutela antecipada não possui os pressupostos para estabilização.

${ }^{9}$ Segundo Fredie Didier, a estabilização disposta no Código concerne aos efeitos da tutela deferida. A coisa julgada incide sobre o conteúdo da decisão. Esse arranjo teórico do autor contribui para diferenciar efeitos da tutela que se estabilizam da coisa julgada, que se refere, exclusivamente, à decisão de mérito proferida no julgamento do mérito da pretensão autoral.
} 
CATHARINA, Alexandre de Castro. Estabilização da tutela antecipada antecedente no processo civil brasileiro: um primeiro balanço

Há intensa polêmica em relação à coisa julgada material da decisão que estabilizou a coisa julgada. A temática é analisada em diversas perspectivas pelos processualistas civis. Retrataremos aqui as principais linhas de pensamento sobre a controvérsia. O Enunciado $\mathrm{n}^{\mathrm{o}} 33$ do Fórum Permanente dos Processualistas Civis dispõe de forma contundente que não cabe ação rescisória nos casos de estabilização da tutela. $\mathrm{O}$ verbete sugere, com efeito, que não há coisa julgada material nos casos em que a tutela antecipada antecedente se estabiliza. Esse entendimento está amparado por determinado setor da doutrina segundo o qual os efeitos da decisão estabilizada não fazem coisa julgada (MARINONI; ARENHART E MITIDIERO, 2015, p. 218).

Em linhas gerais, esta corrente defende que a sumariedade do procedimento de estabilização da tutela antecedente é incompatível com a coisa julgada material, que é inerente à cognição exauriente. Nesses casos, a decisão cujos efeitos se estabilizaram poderá ser impugnada no prazo prescricional ou decadencial do direito material (MARINONI; ARENHART E MITIDIERO, 2015, p. 218). Esse segmento doutrinário sustenta que, após o esgotamento do prazo de 02 anos para impugnação da decisão, poderá o réu ou o interessado propor ação autônoma, desconstitutiva, no prazo decadencial ou prescricional ${ }^{10}$.

Em outra perspectiva de análise, autores como Bruno Redondo (2015) sustentam a existência de coisa julgada material após o esgotamento do prazo decadencial de 02 anos (art. 304 do CPC). Com efeito, esgotado o prazo para propositura da ação de impugnação, exsurge a coisa julgada material, somente impugnável por meio de ação rescisória nos termos do art. 966 do Código de Processo Civil. Nesse caso, a decisão proferida no procedimento da tutela antecipada antecedente se torna imutável.

Partindo de outra premissa teórica, há entendimento no sentido de que é possível estabelecer procedimentos judiciais que dispensam a coisa julgada (DOTTI, 2015). Para esse segmento doutrinário, com amparo na experiência de alguns ordenamentos processuais europeus, há determinadas situações jurídicas que exigem resolução eficaz e célere, dispensando a definitividade inerente à coisa julgada material. Trata-se de entendimento interessante, embora não guarde relação com a cultura jurídica processual (CATHARINA, 2015) estabelecida no Brasil, fortemente assentada na coisa julgada e na segurança jurídica.

\footnotetext{
${ }^{10}$ Há outros posicionamentos sobre a temática. Para Rosalina Costa e Yasmin Curvelo (2018), não é possível admitir a coisa julgada material em sede de estabilização de tutela como também não há como se atribuir outro prazo (decadencial ou prescricional) para que o réu apresente impugnação. Para as autoras, o réu poderá impugnar a decisão estabilizada quando for demandado novamente pelo réu. As hipóteses em que essa possibilidade poderá efetivamente ocorrer não restaram claro no trabalho das autoras. Em outra linha de análise, Roberto Gouveia, Ravi Peixoto e Eduardo Costa (2016) defendem que não há coisa julgada e sim um novo fenômeno denominado imutabilidade das eficácias antecipadas.
} 
CATHARINA, Alexandre de Castro. Estabilização da tutela antecipada antecedente no processo civil brasileiro: um primeiro balanço

Os tribunais superiores ainda não se manifestaram acerca da existência, ou não, de coisa julgada material nos casos em que a decisão que defere a tutela antecipada antecedente se estabiliza, o que prolongará por algum tempo a celeuma sobre a questão.

Por fim, ressalta-se que o código não tratou em detalhes do exercício do contraditório no procedimento de tutela antecedente. A tutela antecipada será deferida liminarmente ou após a justificação prévia. Nos casos que dispensam justificação prévia, o contraditório será postecipado para o julgamento do recurso interposto (art. 1.015, I) pelo réu ${ }^{11}$. O contraditório, neste contexto, se revela, tão somente, como forma de inviabilizar a estabilização da tutela antecipada antecedente. A participação do réu na formação da decisão proferida em tutela antecipada antecedente pode ensejar a redução da resistência acerca da coisa julgada material nos casos de estabilização da decisão que concede a tutela antecipada.

Como se constatou acima, o regramento do instituto não é exaustivo, o que exigirá da doutrina e da jurisprudência aperfeiçoamento permanente, de modo a dar maior aplicabilidade ao instituto da estabilização da tutela antecipada antecedente e, como consequência, propiciar maior efetividade em casos que não exijam maior dilação probatória ou mesmo quando a situação fática exigir. Por essa razão, propomos neste estudo analisar o impacto da inovação legislativa na prática dos tribunais, de modo a compreender a dimensão pragmática do instituto e verificar quais aspectos exigem aprimoramento normativo.

\section{Estabilização da tutela antecipada antecedente nos tribunais}

O Código de Processo Civil entrou em vigor em $2016^{12}$. Seu curto período de vigência contribui, sobremaneira, para que suas principais inovações, como negócio processual atípico e a própria estabilização da tutela antecipada, ainda não tenham sido plenamente assimilados, tanto pela literatura especializada como também pela comunidade jurídica em geral. O Superior Tribunal de Justiça, principal órgão judicial em interpretação de legislação federal, ainda não se pronunciou sobre diversas inovações do código.

Essas limitações conceituais e institucionais, que são muito naturais quando um ordenamento jurídico entra em vigor numa determinada cultura jurídica, inviabilizam uma ampla análise do impacto da estabilização da tutela antecipada na processualística brasileira. Não obstante, é possível, sim, a partir da análise de algumas decisões judiciais, compreender as

\footnotetext{
${ }^{11}$ Conforme foi abordado acima, o réu poderá optar por apresentar contestação ao invés de interpor recurso de agravo de instrumento.

${ }^{12}$ A Lei n ${ }^{\circ}$ 13.105/2015 foi sancionada em 16/03/2015 e entrou em vigor no dia 16/03/2016, considerando o período de vacatio legis de 01 ano.
} 
CATHARINA, Alexandre de Castro. Estabilização da tutela antecipada antecedente no processo civil brasileiro: um primeiro balanço

principais questões debatidas no Poder Judiciário sobre determinada inovação legislativa. Com amparo nos aportes da metodologia qualitativa (BECKER, 2007), coletamos nos sítios dos Tribunais de Justiça dos Estados de cada região do país, algumas decisões monocráticas ou acórdãos que utilizaram a expressão estabilização da tutela antecipada no período de 2019.

A escolha da amostra considerou dois aspectos importantes. As questões jurídicas debatidas no procedimento de estabilização da tutela antecipada podem ser decididas sem que haja interposição de recurso. Nesses casos, a coleta de dados fica inviabilizada, pois não há, na publicidade da produtividade dos órgãos de primeira instância, esta informação. O segundo aspecto diz respeito à extensão da amostra. Apesar da busca nos sítios dos Tribunais de Justiça dos Estados, contemplando todas as regiões do país, não foi localizado julgado algum sobre estabilização da tutela antecipada antecedente nos Estados do Amazonas, Sergipe, Ceará, Maranhão e Mato Grosso do Sul. Nos Estados do Pará e Distrito Federal foram encontrados apenas um julgado, em cada Tribunal, sobre a temática ${ }^{13}$.

A escassez de dados em determinados Estados não pode, em absoluto, sugerir que a comunidade jurídica destas localidades não tenha assimilado o instituto ou mesmo que a aplicabilidade é inviável. Inúmeras variáveis interferem nessa inferência. Não há uniformização sobre como os dados sobre a estabilização da tutela antecipada antecedente são indexadas pelos sítios dos tribunais, o que pode comprometer, consideravelmente, a análise acerca da aplicabilidade do instituto em análise. Por outro lado, é possível que tutelas antecipadas antecedentes tenham sido estabilizadas sem interposição de recursos, o que contribui para que esse dado da realidade judicial não seja captado pela pesquisa no âmbito da segunda instância.

Partindo desta premissa metodológica, é importante ressaltar que o trabalho debaterá, a partir das decisões coletadas no âmbito dos Tribunais de Justiça dos Estados, quais são as principais questões e dúvidas sobre a estabilização da tutela antecedente, de modo a inferir em que medida a inovação legislativa aderiu à cultura jurídica brasileira. Nesse contexto, não serão analisadas todas as decisões encontradas, mas tão somente aquelas que tragam maior diversidade de questões sobre o tema analisado.

No Tribunal de Justiça do Estado de Minas Gerais, há decisões no sentido de fixar honorários advocatícios sucumbenciais nos casos em que a tutela antecipada antecedente foi deferida e posteriormente estabilizada. A maior parte dos resultados da busca realizada no sítio

\footnotetext{
${ }^{13}$ Importante destacar que a busca nos sítios dos Tribunais depende das palavras que compõem as ementas. É provável que nos referidos Tribunais tenham ocorrido julgamentos de tutelas antecipadas antecedentes, mas a ementa do julgado tenha utilizado outras palavras para registrar a decisão na plataforma. Por essa razão, não há como assegurar, de forma categórica, que nos Tribunais em que não obtivemos resultados não houve requerimento de tutela antecipada antecedente.
} 
do referido tribunal apontaram nesta direção. Depreendem-se da ementa do julgado os principais fundamentos para a fixação dos honorários do advogado:

EMENTA: APELAÇÃO CÍVEL - PEDIDO DE TUTELA ANTECIPADA EM CARÁTER ANTECEDENTE - RECURSO EXCLUSIVAMENTE QUANTO AOS HONORÁRIOS SUCUMBENCIAIS - FIXAÇÃO: DEVIDA -EXORBITÂNCIA REDUÇÃO. I - A estabilização da tutela antecipada requerida em caráter antecedente, em razão da ausência de recurso pelo requerido, não obsta a fixação dos honorários sucumbenciais. II - Na medida em que "ratio ubi eadem est, debet eadem iuris dispositivo" (onde a razão é a mesma, a mesma deve ser a disposição do direito), temse que o mesmo critério previsto para o arbitramento dos honorários advocatícios sucumbenciais nas ações em que dado baixo valor à causa ou cujo proveito econômico seja inestimável/irrisório deve igualmente ser utilizado para encabrestar o arbitramento desses honorários nas ações em que sobremodo elevado o valor da causa ou cujo proveito econômico seja exorbitante, ou seja, também nessas últimas ações é possível proceder à definição dos honorários advocatícios sucumbenciais por apreciação equitativa, observados o zelo do causídico, o lugar da prestação do serviço, a natureza e importância da causa, o trabalho realizado pelo advogado e o tempo exigido para o seu serviço (Apelação $\mathbf{n}^{\mathbf{0}}$ 0070342-18.2016.8.13.0461- TJMG)

EMENTA: APELAÇÃO CÍVEL. ESTABILIZAÇÃO DA TUTELA DE URGÊNCIA. ÓBITO DA PARTE AUTORA E INTERPOSIÇÃO DE AGRAVO DE INSTRUMENTO. IMPOSSIBILIDADE. CUSTAS PROCESSUAIS E HONORÁRIOS ADVOCATÍCIOS. CAUSALIDADE. RECURSO PARCIALMENTE PROVIDO. 1. O falecimento da parte autora, em favor da qual deferida a medida de urgência, na modalidade tutela antecipada, não autoriza a estabilização dos efeitos da tutela provisória, mormente quando contra a decisão que deferiu a tutela provisória foi interposto o recurso de agravo de instrumento, ainda que desprovido. 2. As custas processuais e os honorários advocatícios devem observar o princípio da causalidade. Existindo elementos indicando que a demanda foi ajuizada em decorrência da negativa indevida de cobertura contratual pela parte ré, deve ser a demandada condenada ao pagamento das custas processuais e honorários advocatícios, porquanto foi quem deu causa à instauração do processo. 3. Recurso parcialmente provido (Apelação Cível 1.0000.18.053284-8/002 TJMG)

No Tribunal de Justiça do Estado de São Paulo, a questão processual debatida diz respeito à possibilidade de estabilização da tutela quando essa possui natureza cautelar. $\mathrm{O}$ julgado em análise firmou entendimento de que somente se admite a estabilização nos casos de tutela antecipada. A ementa do julgado é peremptória neste sentido:

Agravo de Instrumento. “Ação de Tutela Provisória”. Concessão de tutela antecipada para obtenção de certidão positiva com efeito de negativa. Decisão na qual foi consignada a necessidade de interposição de recurso pela municipalidade para evitar a estabilidade de que trata o art. 304, caput, do CPC/2015. Pretensão à reforma. Acolhimento em parte. Decisão que concedeu tutela de urgência de natureza cautelar (suspensão da exigibilidade art. 151 do CTN). Caso em que não há que se falar em estabilização da tutela. Decisão reformada em sua parte final, mas mantida no que pertine à suspensão da exigibilidade do ISS. Recurso provido em parte. (Agravo de Instrumento n. 2093270-83.2019.8.26.0000 - TJSP) 
CATHARINA, Alexandre de Castro. Estabilização da tutela antecipada antecedente no processo civil brasileiro: um primeiro balanço

No Tribunal de Justiça do Estado do Rio de Janeiro, há julgados em que o cerne da discussão diz respeito ao momento em que a tutela é estabilizada e às consequências processuais da ausência de aditamento da tutela antecipada antecedente, conforme ementas transcritas abaixo:

\footnotetext{
Agravo de instrumento. Tutela cautelar antecedente. Tutela antecipada deferida. Ré que apresentou contestação e reconvenção com documentos. Tutela antecipada revogada. Autora/agravante que alega descumprimento do art. 304 do CPC, a ensejar a estabilização da tutela. Art. 304 que se aplica às hipóteses em que ambas as partes se conformam com a tutela deferida. Estabilização que só ocorre quando não há qualquer tipo de impugnação da parte contrária. Contestação apresentada pela ré que contém pedido de revogação da tutela concedida. Acerto da decisão. Recurso conhecido e desprovido (Agravo de Instrumento $\mathbf{n}^{\circ}$ 0016916-46.2019.8.19.0000 TJRJ)
}

DIREITO PROCESSUAL CIVIL E DIREITO DO CONSUMIDOR. SAÚDE SUPLEMENTAR. SUL AMÉRICA. PACIENTE, MENOR DE IDADE, DIAGNOSTICADO COM TRANSTORNO DO ESPECTRO AUTISTA. PRETENSÃO CONDENATÓRIA EM OBRIGAÇÃO DE FAZER CUMULADA COM COMPENSATÓRIA DE DANOS MORAIS. PEDIDO CONSTANTE COMO “TUTELA ANTECIPADA EM CARÁTER ANTECEDENTE". PRETENSÃO DE CONCESSÃO DA TUTELA PROVISÓRIA DE URGÊNCIA, COM BASE NO ART. 300 DO CÓDIGO DE PROCESSO CIVIL, PARA PRESTAÇÃO DE TRATAMENTO ESPECIALIZADO. TUTELA DE URGÊNCIA DEFERIDA NESTES TERMOS. AGRAVO DE INSTRUMENTO VISANDO TÃO SOMENTE O AFASTAMENTO DA ESTABILIZAÇÃO DA TUTELA, SEM ADENTRAR NO MÉRITO. NÃO TENDO SIDO A TUTELA PROVISÓRIA DE URGÊNCIA CONCEDIDA NOS TERMOS DO ARTIGO 303, DO CÓDIGO DE PROCESSO CIVIL, NÃO HÁ QUE SE FALAR EM PERIGO DA ESTABILIZAÇÃO DA TUTELA. RECURSO NÃO CONHECIDO, COM AMPARO NA REGRA DO ART. 932, III, DO CÓDIGO DE PROCESSO CIVIL (Agravo de Instrumento n 000665386.2018.8.19.0000 - TJRJ)

No Tribunal de Justiça do Estado do Paraná, há alguns poucos julgados em que se debateu se é possível a estabilização da tutela antecipada antecedente após a contestação apresentada pelo requerido ao requerimento formulado, conforme se depreende da ementa abaixo:

APELAÇÃO CÍVEL. TUTELA ANTECIPADA EM CARÁTER ANTECEDENTE. LITISPENDÊNCIA. INOCORRÊNCIA. NECESSÁRIA A IDENTIDADE DE PARTES, CAUSA DE PEDIR E PEDIDO. AÇÕES PROPOSTAS PELA APELADA QUE POSSUEM CAUSA DE PEDIR REMOTA DIVERSA. ALEGAÇÃO DE PREVENÇÃO DA JUSTIÇA FEDERAL QUE TAMBÉM DEVE SER REJEITADA. REUNIÃO DE AÇÕES QUE É VEDADA QUANDO IMPLICAR ALTERAÇÃO DE COMPETÊNCIA ABSOLUTA. ENTENDIMENTO DO STJ. ESTẢBILIZAÇÃO DA TUTELA ANTECIPADA. IMPOSSIBILIDADE. RÉ QUE APRESENTOU CONTESTAÇÃO IMPUGNANDO A TUTELA DEFERIDA, BEM COMO OS FUNDAMENTOS APRESENTADOS PELA AUTORA. INTERPRETAÇÃO DO ARTIGO 304 DO CÓDIGO DE PROCESSO CIVIL. INSURGÊNCIA EM FACE DA TUTELA QUE NÃO SE LIMITA SOMENTE A INTERPOSIÇÃO DE AGRAVO DE INSTRUMENTO. PROCESSO QUE DEVE TER REGULAR PROSSEGUIMENTO, CONFORME PREVISTO PELO $\S 1^{\circ}$ DO ARTIGO 303 DO CPC. SENTENÇA ANULADA. ANÁLISE DO RECURSO ADESIVO PREJUDICADA. RECURSO DE APELAÇÃO CONHECIDO E 
PARCIALMENTE PROVIDO. 1. Não há que se falar em litispendência ou prevenção da justiça federal para julgamento da ação, uma vez que não há identidade da causa de pedir entre a presente ação e o mandado de segurança impetrado, além de que a competência dos referidos juízos é absoluta e não se altera por conexão ou continência. 2. Não há que se falar em estabilização da tutela, uma vez que após ser citada a ré apresentou sua contestação e impugnou os pontos da tutela antecipada, sendo evidente a oposição ao pedido inicial. 3. Por interpretação ao artigo 304 do CPC, possível concluir que a apresentação de contestação impede a estabilização da tutela, razão pela qual a sentença deve ser anulada para que o processo tenha seu regular prosseguimento. 4. Recurso de apelação conhecido e parcialmente provido. 5. Recurso adesivo prejudicado. (Apelação Cível $n^{\circ}$ 7.0067499-11.2018.8.16.0014 - TJPR)

Identificamos no Tribunal de Justiça de Santa Catarina julgados com o mesmo teor, em que se fez reverberar a tese fixada pelo Superior Tribunal de Justiça no sentido de que a tutela antecipada antecedente não se estabiliza nos casos em que o requerido apresente contestação, a despeito de não ter interposto recurso. A transcrição abaixo evidencia a questão jurídica debatida:

\begin{abstract}
AGRAVO DE INSTRUMENTO. AÇÃO REIVINDICATÓRIA. DECISÃO QUE REVOGOU A TUTELA ANTECIPADA ANTERIORMENTE CONCEDIDA. INSURGÊNCIA DO AUTOR. ALEGAÇÃO DE ESTABILIZAÇÃO DOS EFEITOS DA TUTELA DE CARÁTER ANTECEDENTE. ARGUMENTO DE QUE NÃO HOUVE A INTERPOSIÇÃO DE RECURSO. DESCABIMENTO. RESISTÊNCIA AOS FATOS INAUGURAIS E PLEITO DE REVOGAÇÃO DA TUTELA FORMULADOS EM PEÇA CONTESTATÓRIA. CLARA EXISTÊNCIA DE INCONFORMISMO DA PARTE ADVERSA. INTERPRETAÇÃO SISTEMÁTICA E TELEOLÓGICA DO ART. 304 DO CÓDIGO DE PROCESSO CIVIL DE 2015. POSICIONAMENTO DO SUPERIOR TRIBUNAL DE JUSTIÇA. POSSIBILIDADE DE MODIFICAÇÃO OU REVOGAÇÃO DURANTE O CURSO PROCESSUAL. INTELIGÊNCIA DO ART. 296 DO DIPLOMA PROCESSUAL CIVIL. AFASTAMENTO DA TESE (Agravo de Instrumento n. ${ }^{\circ}$ 4014361-47.2019.8.24.0000 - TJSC)
\end{abstract}

Essa questão jurídica também perpassa o Tribunal de Justiça do Estado do Rio Grande do Sul, conforme ementa do julgado abaixo:

APELAÇÃO CÍVEL. INTERNAÇÃO COMPULSÓRIA. PRELIMINAR. INTEMPESTIVIDADE. REJEIÇÃO. MÉRITO. RECEBIMENTO DA INICIAL COMO PEDIDO DE TUTELA ANTECEDENTE. DESCABIMENTO. DESCONSTITUIÇÃO DA DECISÃO RECORRIDA. PRELIMINAR Não merece ser acolhida a preliminar de intempestividade, pois, considerando a prerrogativa de prazo recursal em dobro dos entes públicos, contados 30 dias úteis a partir da intimação pessoal, o recurso foi protocolado tempestivamente. MÉRITO A presente ação ordinária, com pedido de antecipação de tutela, postulando a internação compulsória em favor de dependente químico, foi recebida como pedido de tutela antecedente. Assim, após o deferimento da liminar, diante da apresentação de contestação pelo Estado, o juízo a quo extinguiu o feito por considerar estabilizada a demanda. Entretanto, de acordo com entendimento do STJ, não é exigível que o demandado, para manifestar resistência à pretensão do demandante, interponha recurso contra decisão que antecipara os efeitos da tutela, nos termos do art. $304, \S 1^{\circ}$, do CPC. Além disso, a adoção de ofício, de procedimento diverso do pretendido na inicial trouxe prejuízo a ambas as partes, sendo de rigor a 
CATHARINA, Alexandre de Castro. Estabilização da tutela antecipada antecedente no processo civil brasileiro: um primeiro balanço

desconstituição da sentença de extinção da lide e determinado o processamento da lide pelo rito ordinário. REJEITARAM A PRELIMINAR. NO MÉRITO, DESCONSTITUÍRAM A SENTENÇA. (Apelação Cível, No 70082480161, Oitava Câmara Cível, Tribunal de Justiça do RS, Relator: Rui Portanova, Julgado em: 1209-2019)

A amostragem dos julgados acima aponta no sentido de que o instituto da estabilização da tutela antecipada antecedente vem sendo apreendida pela prática forense e, sobretudo, está sendo aprimorada pela doutrina e pela jurisprudência. Alguns aspectos que não estão claros, do ponto de vista normativo, estão sendo delineados na dinâmica da atividade judicial, o que evidencia a importância da inovação legislativa. É importante, portanto, fazer um balanço da aplicabilidade do instituto em nossa prática judiciária.

\section{Um primeiro balanço sobre a estabilização da tutela provisória no processo civil brasileiro}

Em 2016, quando o Código de Processo Civil entrou em vigor, muito se questionou acerca da aplicabilidade, em nossa cultura jurídica processual, de alguns institutos processuais. Há dúvidas, ainda, sobre o funcionamento do sistema de precedentes judiciais (art. 926); sobre os limites e a extensão dos negócios processuais atípicos e, também, sobre os limites do poder geral de efetivação do juiz para deferimento de atos executivos atípicos (art. 139, IV). A mesma situação ocorre com a estabilização da tutela antecipada antecedente.

No que tange à estabilização da tutela antecipada antecedente, não se vislumbrou, em termos pragmáticos, como o instituto seria assimilado pela comunidade jurídica, principalmente se concebermos que a tutela cautelar satisfativa, que originou em certo sentido o instituto examinado, foi combatida pela literatura especializada em razão de sua impropriedade técnica ${ }^{14}$. Não havia doutrina consolidada no Brasil sobre essa modalidade de cognição sumária por ocasião do início da vigência do Código de Processo Civil de 2015.

As dificuldades iniciais em relação ao instituto não se limitaram ao campo teórico ou científico. No campo prático, mais especificamente no âmbito da advocacia, muitas dúvidas surgiram em relação à forma como o requerimento de tutela antecipada antecedente deve ser formulado. Tal dificuldade é compreensível. A teoria do processo traz como elementos essenciais da demanda as partes, a causa de pedir e o pedido, entendido este último como a pretensão de direito material. A formulação de pedido de mérito integra a estrutura mental da

\footnotetext{
${ }^{14}$ A tutelar cautelar possui natureza assecuratória, cujo principal escopo é garantir a eficácia do processo principal. Partindo dessa premissa conceitual, não se pode alcançar a satisfação da tutela pretendida pelo autor por meio de medida cautelar.
} 
CATHARINA, Alexandre de Castro. Estabilização da tutela antecipada antecedente no processo civil brasileiro: um primeiro balanço

advocacia brasileira. Logo, não se vislumbra formular requerimento de tutela antecipada sem pedido principal ou de mérito, uma vez que isso não faz parte do senso comum dos juristas brasileiros (WARAT, 1994).

As principais inovações normativas trazidas pelo Código de Processo Civil de 2015 tiveram inspiração no direito comparado. Nesta toada, o Incidente de Resolução de Demandas Repetitivas, com inspiração no direito alemão, a dinâmica dos precedentes judiciais, inspirada nos países de cultura jurídica anglo saxônica, o próprio instituto da estabilização da tutela antecipada antecedente, com forte matiz no direito francês e italiano, e, por fim, o negócio processual atípico, inspirado no direito norte-americano, são exemplos dessa inspiração. As inovações foram inseridas em nosso ordenamento jurídico processual sem que fosse elaborada, previamente, uma teoria do processo que desse conta, do ponto de vista epistemológico, desta mudança de paradigma.

Portanto, se faz necessária uma reformulação no ensino jurídico e, mais especificamente, no ensino do direito processual civil, para que se adeque ao modelo de processo implementado pelo Código de Processo Civil de 2015 (CATHARINA, 2018). Verificou-se, na análise acerca da possibilidade da existência da coisa julgada material da decisão que defere a tutela antecipada antecedente, que maior divergência em relação à questão decorre da dificuldade de se conceber um procedimento de cognição sumária que dispense a coisa julgada material, como bem apontou Rogéria Dotti (2018). A coisa julgada e a segurança são vetores axiológicos em nosso ordenamento jurídico, mas a coisa julgada é necessária neste modelo de cognição sumária?

O primeiro balanço apresentado acima, de cunho teórico, se revelou assertivo no tratamento do instituto. Embora o tratamento normativo dado à tutela antecipada antecedente tenha sido insuficiente, é certo que a doutrina vem apresentando soluções adequadas e suficientes para aprimoramento desta técnica de cognição sumária. Questões sobre o cabimento de honorários advocatícios sucumbenciais nos casos de estabilização da tutela antecedente e requisitos para estabilização (PINHO, 2019) vêm sendo pacificadas na doutrina processual. Questões outras, mais polêmicas, como a coisa julgada material e o cabimento da estabilização da tutela antecipada antecedente em face da Fazenda Pública (PINHO, 2019) permanecem em aberto em sede doutrinária. Entretanto, é relevante destacar que há grande esforço da doutrina para compreender e aprimorar o instituto, o que sugere, num primeiro balanço, que o instituto foi incorporado intensamente pela teoria do processo produzida no Brasil.

Há outra dimensão importante a considerar. Além da recepção doutrinária de um instituto, é fundamental que esse seja tratado adequadamente pelos tribunais. No caso da 
CATHARINA, Alexandre de Castro. Estabilização da tutela antecipada antecedente no processo civil brasileiro: um primeiro balanço

estabilização da tutela antecipada antecedente, a estabilidade da jurisprudência ganha relevo em razão mesmo da insuficiência normativa do instituto.

Pode-se inferir duas conclusões a partir dos dados coletados. A primeira diz respeito à utilização do instituto em nossa prática judiciária. Na maior parte dos tribunais pesquisados, houve número considerável de julgados no âmbito da $2^{\mathrm{a}}$ Instância, o que reflete o crescimento gradual desta técnica de cognição sumária. Este dado não pode ser desconsiderado. Tribunais com grande volume de processos, como Minas Gerais, Rio de Janeiro, São Paulo, Paraná e Rio Grande do Sul apresentaram números razoáveis de casos julgados em grau de recurso. Num quadro de congestionamento da estrutura judiciária em todas as regiões do país, a tutela antecipada antecedente vem contribuindo, em alguma medida, para se alcançar a tutela jurisdicional adequada, efetiva e tempestiva (MITIDIERO, 2012, p. 214).

É curial sublinhar que as decisões analisadas acima não contemplam, na integralidade, os casos em que foi requerida tutela antecipada antecedente. Em diversos casos, a tutela antecipada antecedente é indeferida e pode, inclusive, ter casos que estabilizaram sem a interposição de recurso, o que inviabiliza a localização desses casos no âmbito da $2^{\mathrm{a}}$ instância. Esse dado "invisível" reforça a inferência sustentada aqui no sentido de que o instituto da tutela antecipada antecedente e, como consequência, a busca de sua estabilização têm utilidade efetiva na busca da tutela jurisdicional efetiva.

A segunda conclusão, que se infere a partir dos dados coletados, refere-se ao papel suplementar da jurisprudência no que tange ao instituto em análise. A teoria dos precedentes ${ }^{15}$ judiciais (BUSTAMANTE, 2012) classifica as decisões judiciais, no âmbito dos tribunais, em persuasiva e vinculante. Será persuasiva a jurisprudência, ou decisão de determinado tribunal superior, que orienta a interpretação de determinado instituto jurídico. Não vincula. Já a decisão que trata de uma determinada situação fática e em seu julgamento apresenta conteúdo normativo não tratado pelo legislador denomina-se precedente judicial, com caráter vinculante em sentido forte. No caso da estabilização do instituto da tutela antecipada antecedente, a atuação dos tribunais é fundamental, sobretudo para eliminar as omissões da legislação.

Neste contexto, verificou-se que algumas dúvidas sobre o procedimento da tutela antecipada antecedente vêm sendo suprimidas pela jurisprudência, o que contribui para o aprimoramento do instituto. Não há regramento sobre fixação de honorários advocatícios sucumbenciais nos casos de estabilização da tutela. Os casos julgados pelo Tribunal de Justiça

\footnotetext{
${ }^{15} \mathrm{O}$ conceito de precedente judicial não é unívoco no Brasil. Considerando as características do modelo de processo brasileiro e a forma como o tema foi regulado no art. 927 do CPC, há autores que defendem a utilização do termo provimentos judiciais vinculantes, como prefere Aluisio Mendes (2017).
} 
CATHARINA, Alexandre de Castro. Estabilização da tutela antecipada antecedente no processo civil brasileiro: um primeiro balanço

do Estado de Minas Gerais são pontuais sobre a questão. O Superior Tribunal de Justiça será instado a se manifestar sobre o tema, mas já há um parâmetro neste sentido pelo tribunal mineiro.

Em outra perspectiva, o Tribunal de Justiça do Estado de São Paulo foi peremptório ao afirmar que não estabiliza a tutela cautelar. A partir da edição da Lei nº 10.444/2002, que incluiu o art. 273, $\S 7^{\circ}$, do Código de Processo Civil de 1973, foi inserido no regime das tutelas de urgência a fungibilidade entre as tutelas de urgência. Observadas as peculiaridades de cada modalidade de cognição sumária (cautelar e antecipada), eventual equívoco do autor da demanda seria suprido pela fungibilidade entre estas técnicas. Entretanto, no que concerne ao requerimento de tutela provisória antecedente, admite-se a estabilização, tão somente, nos casos de tutela antecipada. Os arestos do Tribunal de Justiça de São Paulo corroboram esta posição, o que contribui para utilização adequada desta técnica de cognição sumária.

O Tribunal do Estado do Rio de Janeiro reforçou a interpretação no sentido de que a estabilização da tutela antecedente se aperfeiçoa com o decurso do prazo para interposição do recurso de agravo de instrumento (art. 1.015, I, do CPC). Os fundamentos utilizados pelo tribunal fluminense articulados com os fundamentos determinantes do Recurso Especial $\mathrm{n}^{\circ}$ 1.760.966/SP evidenciam, de forma unívoca, os requisitos para estabilização, quais sejam a) requerimento do autor e b) ausência de impugnação do réu, independente da via eleita (agravo de instrumento ou contestação). Exsurge da análise dos dados coletados a importância dos tribunais locais para o aprimoramento da técnica desta cognição sumária.

Há, portanto, um primeiro balanço assertivo acerca da funcionalidade da estabilização da tutela antecipada antecedente no processo civil brasileiro. E esta funcionalidade, ou aderência ao instituto, resulta do esforço epistemológico da processualística brasileira no sentido de aprimorar técnicas para superação dos males que decorrem da morosidade processual ao longo dos anos. Por outro lado, a utilização gradual desta técnica é salutar para reduzir as consequências do fenômeno da judicialização de diversas dimensões da vida social, permitindo aos cidadãos e ao próprio Poder Judiciário reduzir consideravelmente o número de conflitos solucionados mediante a técnica de cognição exauriente, resolvendo determinados conflitos por meio desta técnica de cognição sumária.

Desde a sanção da Lei nº 8.952/1994, que alterou a redação do art. 273 do CPC de 1973 e as reformas processuais que lhe sucederam, o instituto da antecipação de tutela, no âmbito do procedimento ordinário, vem sendo aprimorado como principal técnica processual para dar maior efetividade ao processo judicial. A literatura especializada e a jurisprudência dos tribunais têm sido essenciais para que o instituto seja assimilado, gradualmente, pela nossa 
CATHARINA, Alexandre de Castro. Estabilização da tutela antecipada antecedente no processo civil brasileiro: um primeiro balanço

cultura jurídica processual. Faz-se necessário avançar no aprimoramento da técnica de estabilização da tutela antecedente.

Portanto, não há dúvidas acerca da importância da tutela antecipada antecedente como técnica fundamental para assegurar, a um só tempo, a efetividade do processo, o acesso à ordem jurídica justa e à duração razoável do processo. O aperfeiçoamento, teórico e prático, deste instituto é necessidade de primeira grandeza em um país como o Brasil, cujos dados acerca da litigiosidade extrapolam índices aceitáveis.

\section{Conclusão}

A tutela antecipada antecedente, conforme foi observado ao longo do trabalho, foi uma das principais apostas do código no sentido de tornar o processo mais célere e efetivo. Embora o tratamento normativo não seja exaustivo, sobretudo no que tange aos aspectos procedimentais, certo é que a técnica da estabilização encontra amparo nos anseios dos jurisdicionados.

Há institutos processuais, como a adaptação do procedimento (art. 139, IV) ou mesmo o negócio processual atípico (art. 190), que não foram assimilados pela comunidade jurídica, principalmente se considerarmos a ausência de decisões judiciais sobre esses temas que chegam aos tribunais de justiça. O mesmo não ocorre com a estabilização da tutela antecipada antecedente.

Faz-se necessário direcionar, ainda mais, os esforços para a compreensão dos limites e extensão desta técnica de aceleração da tutela jurisdicional, de modo a viabilizar o aprimoramento da atividade judicial além de tornar o processo não só um método de resolução de conflitos, mas, principalmente, um instrumento de efetivação dos direitos fundamentais. Este trabalho é, em verdade, um esforço, ainda que embrionário, neste sentido.

Algumas medidas serão essenciais para se alcançar este objetivo. Primeiramente se faz necessário reformular o ensino jurídico para se dar atenção especial a tutelas provisórias no âmbito do Código de Processo Civil. A tutela antecipada e a tutela cautelar se reformularam no modelo de processo implantado pelo novo ordenamento processual. Desta forma, assegura-se a formação de uma geração de profissionais de direito com conhecimento sólido acerca deste modelo de processo, principalmente sobre suas técnicas de cognição sumária.

Em um segundo momento, faz-se necessário realizar esforços para aprimorar os profissionais formados sob a égide do modelo processual estruturado pelo Código de Processo Civil de 1973. Esses profissionais necessitam de reciclagem permanente por meios das 
CATHARINA, Alexandre de Castro. Estabilização da tutela antecipada antecedente no processo civil brasileiro: um primeiro balanço

respectivas instituições jurídicas às quais estão vinculados. Assim, a reciclagem permanente sobre estabilização da tutela antecipada antecedente, no âmbito das Escolas Superiores da Advocacia, da Escola da Magistratura, nos níveis estadual e federal, como também das Escolas da Advocacia Pública, é medida necessária e premente. Essa conjugação de esforços contribuirá, sobremaneira, para o aprimoramento desta técnica de cognição sumária em nossa processualística.

\section{Referências}

AMAZONAS. Tribunal de Justiça do Estado do Amazonas. Disponível em https://consultasaj.tjam.jus.br/esaj/portal.do? servico=789900. Acesso em: 05 out. 2019.

BARBOSA MOREIRA, José Carlos. O Futuro da Justiça: alguns mitos. In: Temas de direito processual, oitava série. São Paulo: Saraiva, 2004. p. 01-14.

BECKER, Howard. Segredos e truques da pesquisa. Trad. Maria Luiza Borges. Rio de Janeiro: Jorge Zahar, 2007.

BRASIL. Lei n⿳10.105, de 16 de março de 2015. Código de Processo Civil. Brasília, DF: Presidência da República, [2015]. Disponível em: <http://www.planalto.gov.br/ccivil_03/_ato2015-2018/lei/I13105.htm> Acesso em: 05 out. 2019.

BRASIL. Superior Tribunal de Justiça. RECURSO ESPECIAL: 1.760.966, SP. Recorrente: L.S.L e Recorrido: P.C.A.C.I. Relatora: Ministro Marco Aurélio Bellizze. Publicado no Diário Oficial da União em 07 dez. 2018. Disponível em: https://ww2.stj.jus.br/processo/pesquisa/. Acesso em: 05 out. 2019.

BUSTAMANTE, Thomas da Rosa de. Teoria do precedente judicial: a justificação e aplicação das regras jurisprudenciais. São Paulo: Noeses, 2012.

CAPPELLETTI, Mauro; GARTH, Bryant. Acesso à justiça. Trad. Ellen Gracie Northflleet. Porto Alegre: Sérgio Antônio Fabris, 1999.

CATHARINA, Alexandre de Castro, Movimentos sociais e a construção dos precedentes judiciais. Curitiba: Juruá, 2015.

CATHARINA, Alexandre de Castro. Ensino Jurídico e Cultura Jurídica Processual: breves reflexões sobre o ensino do Direito Processual Civil na vigência do CPC/2015. Revista Interdisciplinar de Direito, [S.1.], v. 15, n. 2, p. 177-186, abr. 2018. ISSN 2447-4290. Disponível em: 〈http://revistas.faa.edu.br/index.php/FDV/article/view/300>. Acesso em: 29 mar. 2020.

CEARÁ. Tribunal de Justiça do Estado do Ceará. Disponível em: https://esaj.tjce.jus.br/cjsg/consultaCompleta.do;jsessionid=84FFC0DEAFF9BDB0716D804 C76102D27.cjsg2. Acesso em: 05 out. 2019. 
COSTA, Rosalina Moitta Pinto da; CURVELO, Yasmin Araújo. A estabilização da tutela antecipatória, suas controvérsias e a possibilidade de modificação da decisão antecipatória após o transcurso in albis do prazo de dois anos. Revista Eletrônica de Direito Processual REDP, Rio de Janeiro, v. 19, n. 3, set./dez. 2018. Disponível em < https://www.epublicacoes.uerj.br/index.php/redp/article/view/31087/27462>. Acesso em 26 mar. 2020.

DIDIER, Fredie. Curso de Direito Processual Civil. vol. 2. 12ª ed. Podivm: Salvador, 2017.

DOTTI, Rogéria. A estabilização da tutela antecipada no CPC de 2015: a autonomia da tutela sumária e a coisa julgada dispensável. Revista Jurídica da Escola Superior da Advocacia da OAB-PR, Curitiba, Ano 3, n. 3, dez. 2018. Disponível em < http://revistajuridica.esa.oabpr.org.br/wp-content/uploads/2018/12/revista_esa_8_04.pdf > Acesso em 24 mar. 2020.

GOUVEIA FILHO, Roberto P. Campos; PEIXOTO, Ravi; COSTA, Eduardo José da Fonseca. Estabilização, imutabilidade das eficácias antecipadas e eficácia da coisa julgada: uma versão aperfeiçoada. Revista Eletrônica de Direito Processual - REDP, Rio de Janeiro, v. 17, n. 2, jul./dez. 2016. Disponível em < https://www.epublicacoes.uerj.br/index.php/redp/article/view/26611/18979> Acesso em 27 mar. 2020.

GRECO, Leonardo. A tutela de urgência e tutela de evidência no Código de Processo Civil de 2014/2015. Revista Eletrônica de Direito Processual - REDP, Rio de Janeiro, v. 14, n. 1, jul./dez. 2014. Disponível em < https://www.epublicacoes.uerj.br/index.php/redp/article/view/14541/15862> Acesso em 27 mar. 2020.

KUHN, Thomas. A estrutura das revoluções científicas. São Paulo: Perspectiva, 2017.

MARANHÃO. Tribunal de Justiça do Estado do Maranhão. Disponível em: http://jurisconsult.tjma.jus.br/\#/home. Acesso em: 05 out. 2019.

MARINONI, Luiz Guilherme; ARENHART, Sérgio Cruz; MITIDIERO, Daniel. Curso de Processo Civil: Tutela dos direitos mediante procedimento comum. São Paulo: Revista dos Tribunais, 2015.

MATO GROSSO DO SUL. Tribunal de Justiça do Estado do Mato Grosso do Sul. Disponível em: https://esaj.tjms.jus.br/esaj/portal.do?servico=789900. Acesso em: 05 out. 2019.

MENDES, Aluisio Gonçalves de Castro. Incidente de resolução de demandas repetitivas: sistematização, análise e interpretação do novo instituto processual. Rio de Janeiro: Forense, 2017.

MINAS GERAIS. Tribunal de Justiça do Estado de Minas Gerais. APELAÇÃO CÍVEL: 0070342-18.2016.8.13.0461. Apelante: R.P.P.C e Apelado: M.O.P. Relator: Peixoto Henriques. Diário da justiça de Minas Gerais, 13 ago. 2019. Disponível em: https://www4.tjmg.jus.br/juridico/sf/proc_complemento2.jsp?listaProcessos=1046116007034 2001. Acesso em: 05 out. 2019. 
MITIDIERO, Daniel. Tendências em matéria de tutela sumária: da tutela cautelar à técnica antecipatória. In DIDIER, Fredie Jr (Org). Reconstruindo a teoria geral do processo. Salvador: Podivm, 2012.

PARÁ. Tribunal de Justiça do Estado do Pará. Disponível em:

http://www.tjpa.jus.br/PortalExterno/institucional/Acordaos-e-Jurisprudencia/168242Pesquisa-de-Jurisprudencia.xhtml. Acesso em: 05 out. 2019.

PARANÁ. Tribunal de Justiça do Estado do Paraná. APELAÇÃO CÍVEL: 006749911.2018.8.16.0014. Apelante: A.C.C E OUTRO e Apelado: C.D.S.A E OUTRO. Relator: Sigurd Roberto Bengtsson. Diário da justiça do Paraná, 30 set. 2019. Disponível em: http://portal.tjpr.jus.br/jurisprudencia/j/4100000009203431/Ac\%C3\%B3rd\%C3\%A3o0067499-11.2018.8.16.0014. Acesso em: 05 out. 2019.

PINHO, Humberto Dalla Bernardino de. Manual de Direito Processual Civil Contemporâneo. São Paulo: Saraiva, 2019.

REDONDO, Bruno. Estabilização, modificação e negociação da tutela de urgência antecipada antecedente: principais controvérsias. Revista de Processo, São Paulo: Revista dos Tribunais, v. 244, jun. 2015. Disponível em <

http://www.mpsp.mp.br/portal/page/portal/documentacao_e_divulgacao/doc_biblioteca/bibli_ servicos_produtos/bibli_boletim/bibli_bol_2006/RPro_n.244.07.PDF> Acesso em 26 mar. 2020.

RIO DE JANEIRO. Tribunal de Justiça do Estado do Rio de Janeiro. AGRAVO DE INSTRUMENTO: 0016916-46.2019.8.19.0000. Agravante: S.C.P e Agravado: R.S.P.L. Relator: Wagner Cinelli de Paula Freitas. Diário da justiça do Rio de Janeiro, 16 maio 2019. Disponível em: http://www4.tjrj.jus.br/ejud/ConsultaProcesso.aspx?N=201900221985. Acesso em: 05 out. 2019.

RIO DE JANEIRO. Tribunal de Justiça do Estado do Rio de Janeiro. AGRAVO DE INSTRUMENTO: 0006653-86.2018.8.19.0000. Agravante: S.A.C.S.S e Agravado: S.A.S.A. Relator: Werson Franco Pereira Rêgo. Diário da justiça do Rio de Janeiro, 19 abril 2018. Disponível em: http://www4.tjrj.jus.br/ejud/ConsultaProcesso.aspx?N=201800208923. Acesso em: 05 out. 2019.

RIO GRANDE DO SUL. Tribunal de Justiça do Rio Grande do Sul. APELAÇÃO CÍVEL: 70082480161, RS. Apelante: I.R.C.V e Apelado: E.R.G.S. Relatora: Rui Portanova. Diário da justiça do Rio Grande do Sul, 12 set. 2019. Disponível em: http://www.tjrs.jus.br/site/buscasolr/index.html?aba=jurisprudencia. Acesso em: 05 out. 2019.

SANTA CATARINA. Tribunal de Justiça do Estado de Santa Catarina. AGRAVO DE INSTRUMENTO: 4014361-47.2019.824.0000. Agravante: A.M.A.V.W e Agravado: Z.C.M. Relator: Carlos Roberto da Silva. Diário da justiça de Santa Catarina, 13 set. 2019. Disponível em: https://esaj.tjsc.jus.br/cposgtj/open.do. Acesso em: 05 out. 2019.

SÃO PAULO. Tribunal de Justiça do Estado de São Paulo. AGRAVO DE INSTRUMENTO: 2093270-83.2019.8.26.0000. Agravante: M.S.C.R.P e Agravado: C.A.R.T. Relator: Ricardo Chimenti. Diário da justiça do Estado de São Paulo, 27 set. 2019. Disponível em: 
CATHARINA, Alexandre de Castro. Estabilização da tutela antecipada antecedente no processo civil brasileiro: um primeiro balanço

https://esaj.tjsp.jus.br/cposg/show.do?processo.foro=990\&processo.codigo=RI0052K9X0000. Acesso em: 05 out. 2019.

SENADO FEDERAL, Exposição de Motivos. Código de processo civil e normas correlatas. - 7. ed. - Brasília: Senado Federal, Coordenação de Edições Técnicas, 2015.

SERGIPE. Tribunal de Justiça do Estado de Sergipe. Disponível em:

https://www.tjse.jus.br/portal/consultas/jurisprudencia/judicial. Acesso em: 05 out. 2019.

THEODORO JUNIOR, Humberto; NUNES, Dierle. BAHIA, Alexandre Melo Franco. PEDRON, Flavio Quinaud. Novo CPC - Fundamentos e sistematização. Rio de Janeiro: Forense, 2015.

WARAT, Luiz Alberto. Introdução geral ao direito. v. 1. Porto Alegre: Sérgio Antonio Fabris Editor, 1994.

WATANABE, Kazuo. Cognição no processo civil. São Paulo: Saraiva, 2012. 